\title{
Free-living energy expenditure of adult men assessed by continuous heart-rate monitoring and doubly-labelled water
}

\author{
BY LINDA DAVIDSON ${ }^{1}$, GERALDINE McNEILL ${ }^{1,2}$, PAUL HAGGARTY ${ }^{1}$, \\ JOHN S. SMITH ${ }^{1}$ AND MICHAEL F. FRANKLIN ${ }^{1}$ \\ ${ }^{1}$ Rowett Research Institute, Greenburn Road, Bucksburn, Aberdeen AB21 9SB \\ ${ }^{2}$ Department of Medicine and Therapeutics, University of Aberdeen, Aberdeen AB25 $2 Z D$
}

(Received 17 January 1997 - Accepted 20 February 1997)

\begin{abstract}
Free-living energy expenditure was estimated by doubly-labelled water (DLW) and continuous heart-rate (HR) monitoring over nine consecutive days in nine healthy men with sedentary occupations but different levels of leisure-time physical activity. Individual calibrations of the HRenergy expenditure (EE) relationship were obtained for each subject using 30 min average values of HR and EE obtained during $24 \mathrm{~h}$ whole-body calorimetry with a defined exercise protocol, and additional data points for individual leisure activities measured with an Oxylog portable $\mathrm{O}_{2}$ consumption meter. The HR data were processed to remove spurious values and insert missing data before the calculation of $\mathrm{EE}$ from second-order polynomial equations relating EE to HR. After data processing, the HR-derived EE for this group of subjects was on average 0.8 (SEM 0.6) MJ/d, or 6.0 (SEM 4.2) \% higher than that estimated by DLW. The diary-respirometer method, used over the same $9 \mathrm{~d}$, gave values which were 1.9 (SEM 0.7) MJ/d, or $-12 \cdot 1$ (SEM 4.0) \% lower than the DLW method. The results suggest that HR monitoring can provide a better estimate of $24 \mathrm{~h} \mathrm{EE}$ of groups than the diary-respirometer method, but show that both methods can introduce errors of $20 \%$ or more in individuals.
\end{abstract}

Energy expenditure: Doubly-labelled water: Heart-rate monitoring

The possibility that heart-rate (HR) monitoring may provide an alternative to whole-body calorimetry or doubly-labelled water (DLW) as a measure of $24 \mathrm{~h}$ energy expenditure (EE) is an attractive one due to the low cost of the HR monitors and the acceptability of HR monitoring for a wide range of subjects. The development of monitors which store minuteby-minute $\mathrm{HR}$ data for periods of $24 \mathrm{~h}$ or more has renewed interest in the method as it is now possible to estimate EE on a minute-by-minute basis rather than deriving a single value based on a mean daily HR. However, initial hopes that the relationship between HR and EE could be established for groups of subjects have not been realized, and the need for individual calibration of HR-EE relationships has been clearly established (Bradfield et al. 1970; Kalkwarf et al. 1989; Li et al. 1993). This requirement increased the complexity of the method, although the cost remains much less than that of DLW. Investigators differ in the mathematical model used to predict EE from HR, although it is generally agreed that an approach which takes account of the difference in the gradient of the relationship between HR and EE at low- and high-intensity activity is needed.

There have been several studies designed to assess the validity of estimates of EE derived from minute-by-minute HR (Table 1). Two studies using whole-body calorimetry as a reference method (Spurr et al. 1988; Ceesay et al. 1989) found reasonably good agreement between the two methods, while another study, using intake balance as the 


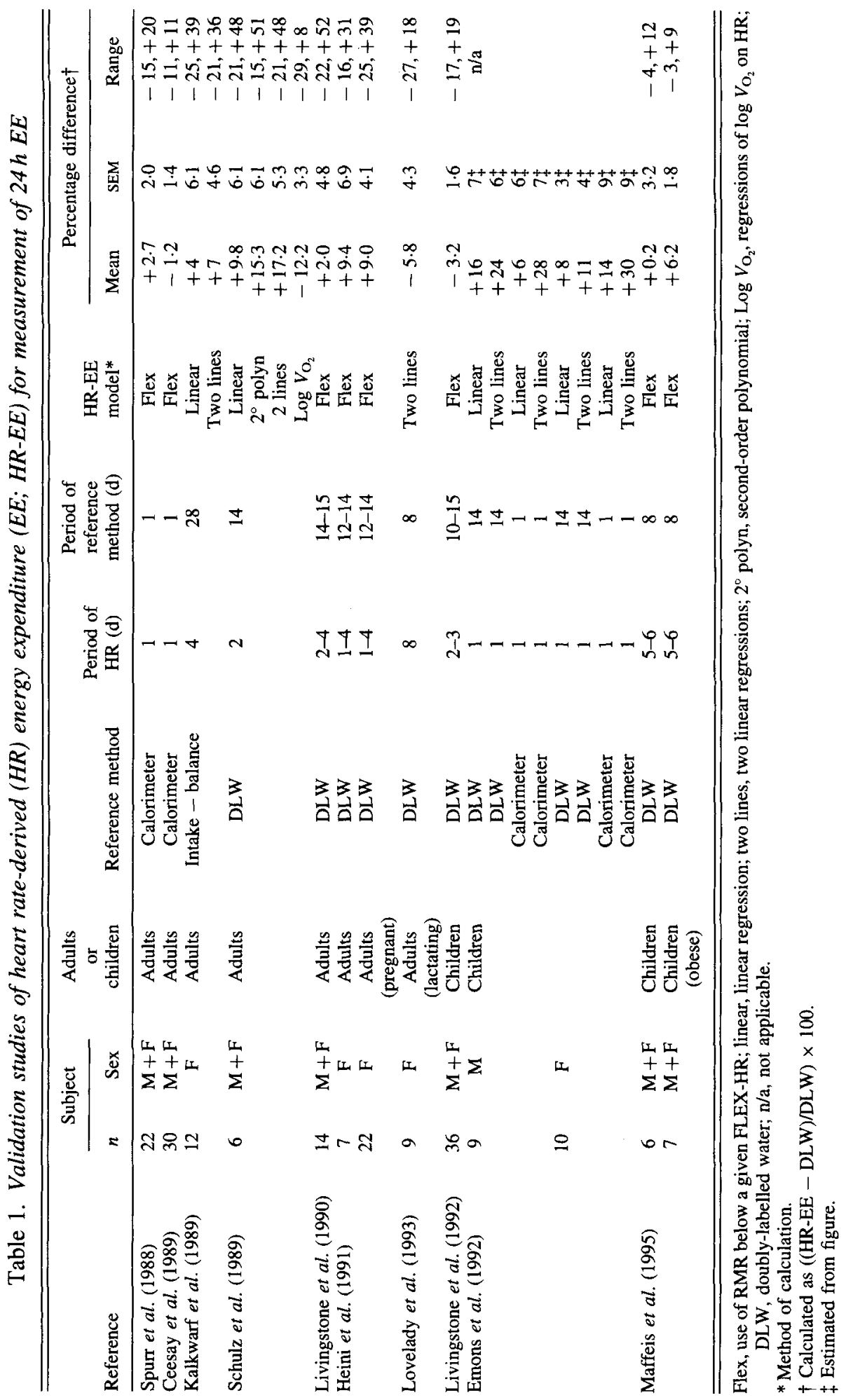


reference method, found less satisfactory agreement (Kalkwarf et al. 1989). More recent studies using DLW as the reference method in adults have found mean differences between HR-derived EE (HR-EE) and DLW-derived EE (DLW-EE) ranging from -12.2 to $+9.4 \%$ (Schulz et al. 1989; Livingstone et al. 1990; Heini et al. 1991; Lovelady et al. 1993). Although these values must be seen in the light of the fact that the estimated error in DLW is $3-5 \%$, there was a wide range of individual errors in all these studies, which casts some doubt on the possibility of using the HR-EE method to classify the EE level of individuals, for example in epidemiological studies. However, in the first three of these studies HR was monitored for a small proportion of the DLW measurement period, so some of the differences between methods could be due to differences in activity between the days of $\mathrm{HR}$ monitoring and those without HR monitoring. Lovelady et al. (1993) monitored HR throughout the DLW study, but expressed concern that errors in the DLW method could have been increased by the high water turnover and low activity levels of their lactating subjects. Heini et al. (1991) also pointed out that the error in the DLW method was increased in their pregnant subjects in the third trimester. One other possible source of error in these studies is the use of HR and EE measured during standardized activities for calibration of the HR-EE relationship. The calibration measurements are usually made with clearly-defined exercises (such as sitting still, cycling on an ergometer or walking on a treadmill) with the subject wearing a mouthpiece and nose clips for collection of expired air. Performance of activities under these conditions may distort the HR-EE relationship from that seen in spontaneous activity, due to the repetitive nature of these activities and possible stress induced by the measurement (Livingstone et al. 1992). In an earlier study Dauncey \& James (1979) showed that the HR-EE relationship derived from measurements in a calorimeter chamber (using mean HR and EE values for $5 \mathrm{~h}$ periods) gave a better prediction of $E E$ in the chamber on a subsequent day than calibrations based on individual measurements of activities.

We report here a $9 \mathrm{~d}$ study of HR-EE and DLW-EE in weight-stable men, using continuous HR monitoring and whole-body indirect calorimetry as the basis for calibration of the HR-EE relationship. To compare the performance of the HR-EE method with the traditional diary-respirometer method, we also estimated EE from a detailed activity diary (AD-EE) kept over the same $9 \mathrm{~d}$ period.

\section{METHODS}

\section{Study protocol}

Nine healthy non-smoking men aged 25-54 years, who had sedentary occupations but leisure activities which varied in intensity, took part in the study. Two of the subjects carried out no leisure activity, and the remaining seven carried out exercise (mainly running, but also gardening, squash and tennis) at levels which ranged from occasional to competitive training. The measurements were made during the summer in Aberdeen as part of a larger study on the effect of season and leisure activity on free-living EE (Haggarty et $a l$. 1994b). The study period included seven weekdays and two weekend days. Subject 5 completed $7 \mathrm{~d}$ rather than $9 \mathrm{~d}$ of HR-EE and DLW-EE monitoring due to illness on days 8 and 9. The study protocol was approved by the Joint Ethical Committee of Grampian Health Board and the University of Aberdeen, and all subjects gave informed written consent to participate. 


\section{$B M R$}

Subjects entered the residential unit at the Rowett Research Institute the evening before the measurement of BMR on day 0 and consumed a standard evening meal providing one-third of the estimated daily energy requirements (Department of Health, 1991). The BMR was measured after an overnight fast for a period of $20 \mathrm{~min}$ by a ventilated-hood indirect calorimeter (McNeill et al. 1988).

\section{Activity diary}

During the $9 \mathrm{~d}$ measurement period the subjects were asked to record the time spent in various coded activities in 5 min blocks. The pre-defined activities were: in bed, dressing, lying, sitting, standing, light housework, heavy housework, walking at a moderate pace, and walking briskly or carrying a load. Additional codes were provided for up to three different kinds of sport activity and five miscellaneous activities to be defined by the subjects. The diary entries were checked every day to ensure complete recording. Measurements of BMR (by ventilated hood) and of the energy cost of activities in the calorimeter chamber and during leisure exercise, measured with the Oxylog, were used in addition to literature values for energy costs of activities (Food and Agriculture Organization/World Health Organization/United Nations University, 1985; James \& Schofield, 1990) to calculate AD-EE.

\section{Heart-rate monitoring}

HR was monitored continuously using a Polar Sports Tester 4000 HR monitor (Polar Elector, Kempele, Finland) during the $9 \mathrm{~d}$ free-living period and during the $24 \mathrm{~h}$ respiration chamber and Oxylog calibration measurements. The Sports Tester comprises a lightweight elastic chest band with built-in rubber electrodes and transmitter, and a wrist-watch microcomputer receiver. The monitor was set to record HR every $1 \mathrm{~min}$ and to store these values for up to $33 \mathrm{~h}$. The logged HR values were transferred daily to a portable computer, after which the HR monitor was reset. The transfer of data took 1-2 min. Each subject was given a spare chest band, so that it could be changed after, for example, showering or heavy exercise, and was provided with written instructions on how to reset the monitor if it stopped recording, and a contact telephone number in case of other problems. The HR monitoring system was well-accepted by the subjects, although the electrode contact was sometimes lost during sleep, particularly in the thinner subjects.

\section{Calibration of heart rate-energy expenditure relationship}

At the end of the free-living study period subjects spent $27 \mathrm{~h}$ in a whole-body respiration chamber at the Rowett Research Institute (McNeill et al. 1989), during which the HR and EE were measured simultaneously. Calibration of the respiration chambers was carried out by periodic combustion of known weights of butane inside the chambers. Subjects entered the chamber between 08.00 and 08.30 hours; HR and EE data recording commenced at 10.50 hours and finished at 11.00 hours the next morning. Meals were served at 09.00 , 13.00 and 18.00 hours, providing a total daily energy intake of $1.55 \times$ measured BMR, consisting of $55 \%$ of energy as carbohydrate, $30 \%$ as fat and $15 \%$ as protein. While in the chamber the subjects followed a controlled activity programme of normal sedentary activities (reading, watching TV, eating, sleeping) and eight 30 min periods of programmed exercise. The programmed activities were: walking at $80 \mathrm{steps} / \mathrm{min}$, stepping on and off a 
$200 \mathrm{~mm}$ high wooden step at 80 steps/min, and cycling on a cycle ergometer (Monark Ergomedic 818e; Varberg, Sweden) at two different levels of expenditure (35 and $75 \mathrm{~W}$ ). EE was calculated for each $30 \mathrm{~min}$ period from the respiratory gas exchange using the Weir (1949) equation.

Measurements of the EE associated with higher-intensity activities recorded in the diary were carried out using an Oxylog portable $\mathrm{O}_{2}$ consumption meter. Subjects wore nose clips and a mouthpiece rather than a face-mask as we have found that the mask may leak in some subjects (Bukkens \& McNeill, 1990). Each measurement lasted 15-20 min, including a 5 min equilibration period which was not used for calculation of HR or EE. EE was calculated from the volume of $\mathrm{O}_{2}$ consumed using an alternative form of the Weir (1949) equation: $\mathrm{EE}=$ volume $\mathrm{O}_{2}$ consumed (litres) $\times K$ (where $K(\mathrm{~kJ} / 1)=16.3+4.6 \mathrm{RQ}$ ), and an assumed $\mathrm{RQ}$ of 1.0. The error in EE associated with this method of calculation is less than $1 \%$ under normal conditions, as the measurement of inspired volume rather than expired volume tends to cancel the error introduced by assuming an RQ of 1.0 (McNeill et al. 1987). The Oxylog $\mathrm{O}_{2}$ sensors were set with $\mathrm{N}_{2}$ and atmospheric air and values for $\mathrm{EE}$ were checked by simultaneous Oxylog and ventilated-hood measurements of resting metabolic rate in eight subjects, which showed a mean difference in resting EE of 3.9 (SEM 0.9) \%.

HR-EE calibration curves were derived for each subject, using the mean 30 min values for $\mathrm{HR}$ and $\mathrm{EE}$ obtained during the $24 \mathrm{~h}$ calorimeter chamber and further data points from Oxylog and HR measurements of the high-intensity activities recorded in the activity diary. A second-order polynomial was fitted to the individual HR-EE relationships using a graphics program (Fig. P, version 4.1; Biosoft, Cambridge). To compare this calculation approach with the FLEX-HR approach used by several other investigators, the HR data were also calculated using the FLEX-HR method as described by Ceesay et al. (1989). The equations obtained from each subject were then used to calculate EE from the free-living HR data.

\section{Insertion and fltering of heart-rate data}

Many HR monitors, including a model similar to that used in the present study, have been shown to record HR which agree well with simultaneous electrocardiogram readings (for example, see Leger \& Thivierge, 1988). However, the continuity of the HR record was occasionally broken, due either to loss of electrode contact or the introduction of spuriously high values due to electrical interference from, for example, computers or car engines. If data were lost for short periods ( $15 \mathrm{~min}$ or less), the values were replaced by the last reliable HR. If data were lost for longer periods, the average HR for periods of the same activity (as shown in the activity diary) was inserted. The percentage of the HR data which was lost was 9.3 (SEM 1.8) \% of the total record. Much of this data was lost during sleep, especially in the thinner subjects, although strapping the electrode to the chest at night in these subjects was found to reduce the loss of electrode contact. HR values which were spuriously high (above 200 beats/min (bpm)) or low (below $30 \mathrm{bpm}$ ) were also removed by a filter ('filter 1'). A second filter ('filter 2') removed values which were implausibly higher or lower than the value for the previous minute.

\section{Measurement of maximum rate of change of heart-rate}

This was measured in all nine subjects of the study. HR was recorded while the subjects lay quietly on a bed for $10 \mathrm{~min}$. They then rapidly mounted a cycle ergometer (Monark Ergomedic $818 \mathrm{e}$ ) and immediately began cycling at $120 \mathrm{~W}$ for 3-5 min, after which they 
lay quietly on the bed for another $10 \mathrm{~min}$ period. After an interval of $45 \mathrm{~min}$ each subject repeated the same procedure at $175 \mathrm{~W}$. The fitter subjects carried out a further measurement at $240 \mathrm{~W}$. HR was logged every $5 \mathrm{~s}$ to avoid the possibility of apparent attenuation of the change due to averaging of a resting and exercise HR occurring in the same minute. The largest changes in HR were observed in the fittest subjects, as they tended to have lower resting HR values and also undertook more strenuous activity. Fig. 1 shows the HR of subject 9 on changing from resting to cycling at $240 \mathrm{~W}$. The maximum rate of change of $\mathrm{HR}$ seen in these measurements was $55 \mathrm{bpm}$.

\section{Doubly-labelled water}

A venous blood sample was taken immediately after the BMR measurement while the subjects were still fasted. They each drank DLW $\left(0.19 \mathrm{~g} \mathrm{H}_{2}{ }^{18} \mathrm{O}\right.$ and $0.24 \mathrm{~g}^{2} \mathrm{H}_{2} \mathrm{O}$ per kg body weight) and a second venous blood sample was taken $3 \mathrm{~h}$ later. A portion of urine was obtained from the second voiding of the day on each day of the study. All samples were analysed for ${ }^{18} \mathrm{O}$ to check that samples had not been mislabelled or contaminated and ${ }^{2} \mathrm{H}$
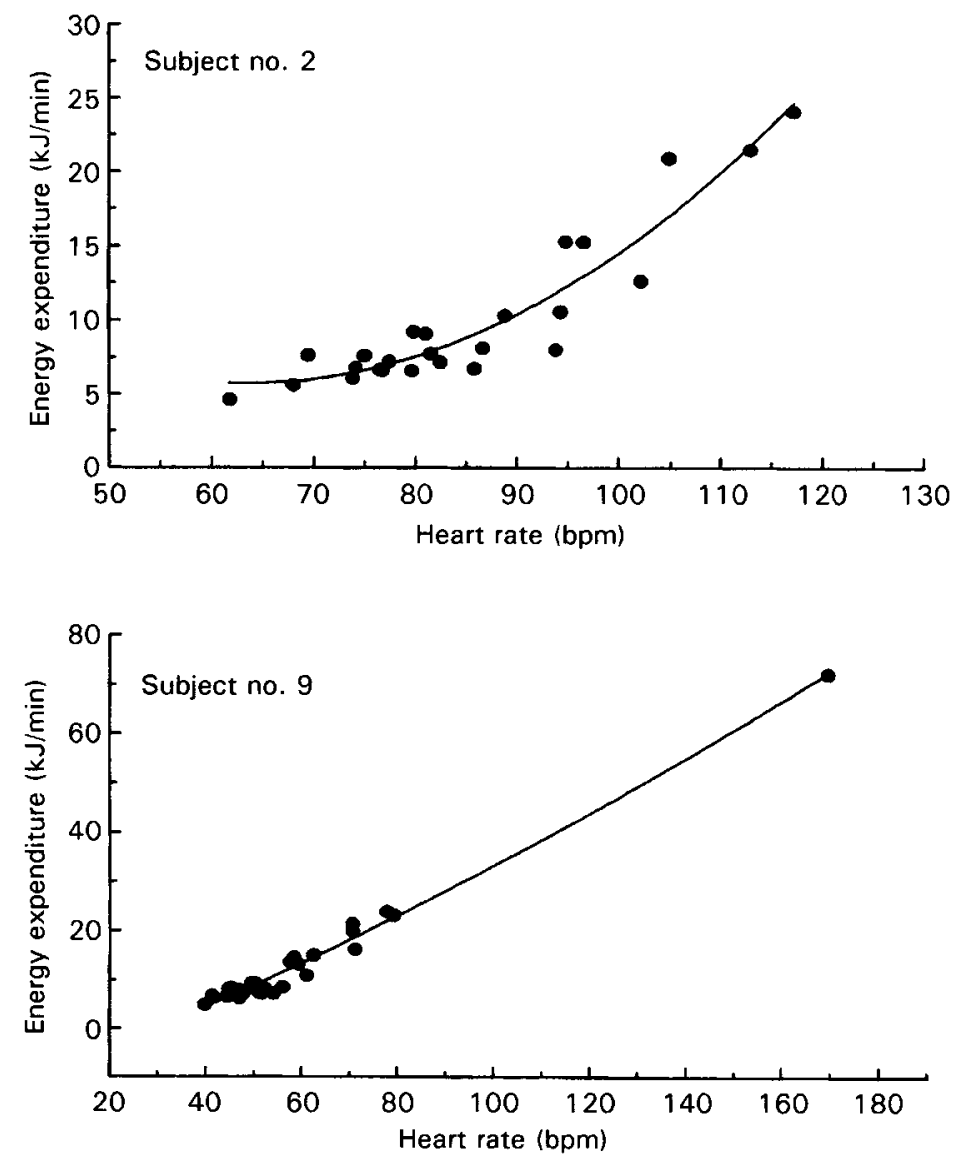

Fig. 1. Heart rate and energy expenditure calibration curves for an inactive subject (subject no. 2) and a very active subject (subject no. 9). For details of subjects and procedures, see Table 1 and pp. 697-698. bpm, Beats/min. 
was measured on the first and last day of the study. The two-point method of calculation was used to estimate the rate constant, and the pool size was determined by the increase in body water enrichment $3 \mathrm{~h}$ after dosing. EE was calculated using the Weir (1949) formula assuming an RQ of 0.85 . Full details of the analysis, calculations and assumptions are given elsewhere (Haggarty et al. 1994b). Physical activity level (PAL) was calculated as DLW-EE/BMR.

\section{Calculation of precision of doubly-labelled water}

A full description of our method of estimating the precision of DLW estimates of EE from multi-point data is described elsewhere (Haggarty et al. 1994a). The same general principle has been followed here with the following equations specific to two-point data:

$$
\begin{aligned}
V(N)= & N^{2}\left[\frac{V(A \mathrm{~mm})}{A \mathrm{~mm}^{2}}+\frac{V(A \mathrm{ppm})}{(A \mathrm{ppm}-B \mathrm{ppm})^{2}}+\frac{V(P \mathrm{ppm})}{(P \mathrm{ppm}-B \mathrm{ppm})^{2}}\right. \\
& \left.+\frac{(A \mathrm{ppm}-P \mathrm{ppm})^{2} \times V(B \mathrm{ppm})}{(A \mathrm{ppm}-B \mathrm{ppm})^{2} \times(P \mathrm{ppm}-B \mathrm{ppm})^{2}}\right], \\
V(k)= & \frac{1}{\left(T_{2}-T_{1}\right)^{2}} \times\left[\left[\left(\frac{1}{\left.T_{2} \mathrm{ppm}-B \mathrm{ppm}\right)}-\frac{1}{\left(T_{1} \mathrm{ppm}-B \mathrm{ppm}\right)}\right)^{2} \times V(B \mathrm{ppm})\right]\right. \\
& \left.+\left(\frac{V\left(T_{1} \mathrm{ppm}\right)}{\left(T_{1} \mathrm{ppm}-B \mathrm{ppm}\right)^{2}}\right)+\left(\frac{V\left(T_{2} \mathrm{ppm}\right)}{\left(T_{2} \mathrm{ppm}-B \mathrm{ppm}\right)^{2}}\right)\right], \\
V(J)= & \left(k^{2} \times V(N)\right)+\left(N^{2} \times V(k)\right), \\
V\left(\mathrm{CO}_{2}\right)= & 1 / 4\left[V\left(J^{18} \mathrm{O}\right)+V\left(J^{2} \mathrm{H}\right)\right],
\end{aligned}
$$

where $N$ is pool size, $k$ is rate constant, $J^{18} \mathrm{O}, J^{2} \mathrm{H}$ are flux of ${ }^{18} \mathrm{O}$ and ${ }^{2} \mathrm{H}, r \mathrm{CO}_{2}$ is rate of $\mathrm{CO}_{2}$ production, $V$ is variance, $T_{1}, T_{2}$ are time of data points 1 and $2, A \mathrm{~mm}$ is molecular mass of dose, $A$ ppm, $B$ ppm, Pppm, $T_{1}$ ppm, $T_{2} \mathrm{ppm}$ are abundance of dose, background, post-dose abundance, first time-point and last time-point.

\section{Data analysis}

Values are expressed as means and standard deviations or with their standard errors. HREE, AD-EE and DLW-EE values were tested for normality (Shapiro \& Wilk, 1965) but no evidence of non-normality was found. The significance of the differences between HR-EE, AD-EE and DLW-EE were compared by the method of Bland \& Altman (1986). Relationships between the errors in HR-EE and other variables were tested by linear regression.

\section{RESULTS}

Table 2 shows the characteristics of the subjects who took part in the study. Subjects 5, 7, 8 and 9 were competitive runners in training, which is reflected in their PAL values of $2.02-2.41 \times$ BMR.

The HR-EE calibration curves for subjects 2 and 9 (representing the two extremes of leisure activity and physical fitness) are shown in Fig. 2. Subject 2 did no sport whereas 
Table 2. Description of subjects, and energy expenditure (EE) derived by doubly-labelled water (DLW) method (DLW-EE)

\begin{tabular}{|c|c|c|c|c|c|c|c|c|}
\hline \multirow{2}{*}{$\begin{array}{l}\text { Subject } \\
\text { no. }\end{array}$} & \multirow{2}{*}{$\begin{array}{c}\text { Age } \\
\text { (years) }\end{array}$} & \multirow{2}{*}{$\begin{array}{l}\text { Height } \\
\text { (m) }\end{array}$} & \multirow{2}{*}{$\begin{array}{l}\text { Wt } \\
(\mathrm{kg})\end{array}$} & \multirow{2}{*}{$\begin{array}{c}\text { BMI } \\
\left(\mathrm{kg} / \mathrm{m}^{2}\right)\end{array}$} & \multirow{2}{*}{$\begin{array}{l}\text { Percentage } \\
\text { fat* }\end{array}$} & \multicolumn{2}{|c|}{ DLW-EE (MJ/d) } & \multirow[b]{2}{*}{$\mathrm{PAL} \dagger$} \\
\hline & & & & & & Mean & SEM & \\
\hline$\overline{1}$ & 25 & 1.61 & 57.2 & $22 \cdot 1$ & 22.94 & $10 \cdot 00$ & 0.26 & 1.50 \\
\hline 2 & 40 & 1.82 & $71 \cdot 1$ & 21.5 & 29.29 & 12.49 & 0.31 & 1.75 \\
\hline 3 & 41 & 1.79 & 62.4 & 19.5 & 17.68 & $12 \cdot 50$ & 0.38 & 1.79 \\
\hline 4 & 36 & 1.81 & 76.8 & 23.4 & 21.80 & 14.64 & 0.44 & 1.95 \\
\hline 5 & 33 & 1.77 & 67.9 & 21.7 & 20.76 & $15 \cdot 92$ & 0.40 & $2 \cdot 26$ \\
\hline 6 & 26 & 1.76 & $70 \cdot 6$ & 22.8 & $20 \cdot 34$ & $15 \cdot 61$ & 0.35 & 2.04 \\
\hline 7 & 43 & 1.73 & $70 \cdot 5$ & 23.6 & 20.76 & $15 \cdot 19$ & 0.34 & 2.02 \\
\hline 8 & 42 & 1.72 & $59 \cdot 1$ & $20 \cdot 0$ & 15.92 & 14.46 & 0.21 & $2 \cdot 36$ \\
\hline 9 & 54 & 1.79 & 64.0 & $20 \cdot 0$ & $10 \cdot 24$ & 19.59 & 0.43 & 2.41 \\
\hline Mean & 38 & 1.76 & $66 \cdot 6$ & $21 \cdot 6$ & 19.96 & 14.49 & 0.35 & $2 \cdot 01$ \\
\hline $\mathrm{SD}$ & 9 & 0.06 & 6.4 & 1.5 & 5.20 & 2.69 & 0.08 & 0.30 \\
\hline
\end{tabular}

PAL, physical activity level.

* Calculated from the $\mathrm{H}_{2}{ }^{18} \mathrm{O}$ pool size as described elsewhere (Haggarty et al $1994 \mathrm{~b}$ ).

$\dagger$ DLW-EE/BMR.

subject 9 was a regular runner. Although these subjects were of a similar age, there was a difference both in the resting HR (60 bpm in subject 2 and $40 \mathrm{bpm}$ in subject 9$)$ and in the EE corresponding to each HR (e.g. for a HR of $80 \mathrm{bpm}$ the EE was $8 \mathrm{~kJ} / \mathrm{min}$ in subject 2 and $22 \mathrm{~kJ} / \mathrm{min}$ in subject 9 ). These differences highlight the need for individual calibration of the HR-EE relationship.

The comparison of HR-EE with DLW-EE is presented in Table 3. The EE derived from the 'raw' HR data (i.e. without insertion or filtering) was significantly higher $(+16.3$ (SEM 4.9) \%; $P=0.01$ ) than the DLW-EE. The overestimate was smaller but remained significantly different after insertion of appropriate HR values where large blocks of data were missing $(+11.6$ (SEM 4.6) \%; $P=0.04)$. After application of filter 1 the difference $(+9.6($ SEM 4.4$) \%)$ was not significant. Filter 2 further improved the agreement between

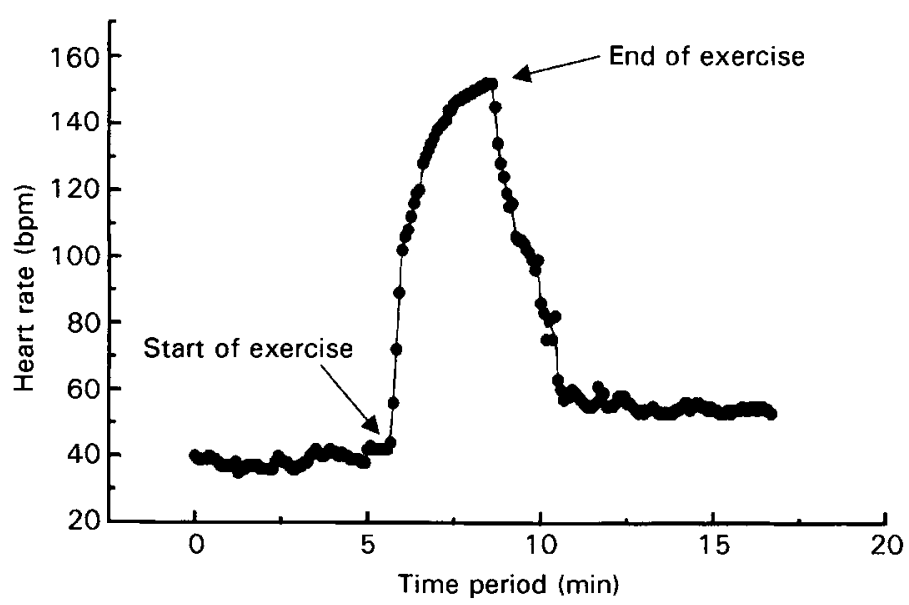

Fig. 2. Rate of change of heart rate on changing from complete rest to cycling at $240 \mathrm{~W}$ for subject no. 9 . For details of subject and procedures, see Table 1 and pp. 697-700. bpm, Beats/min. 


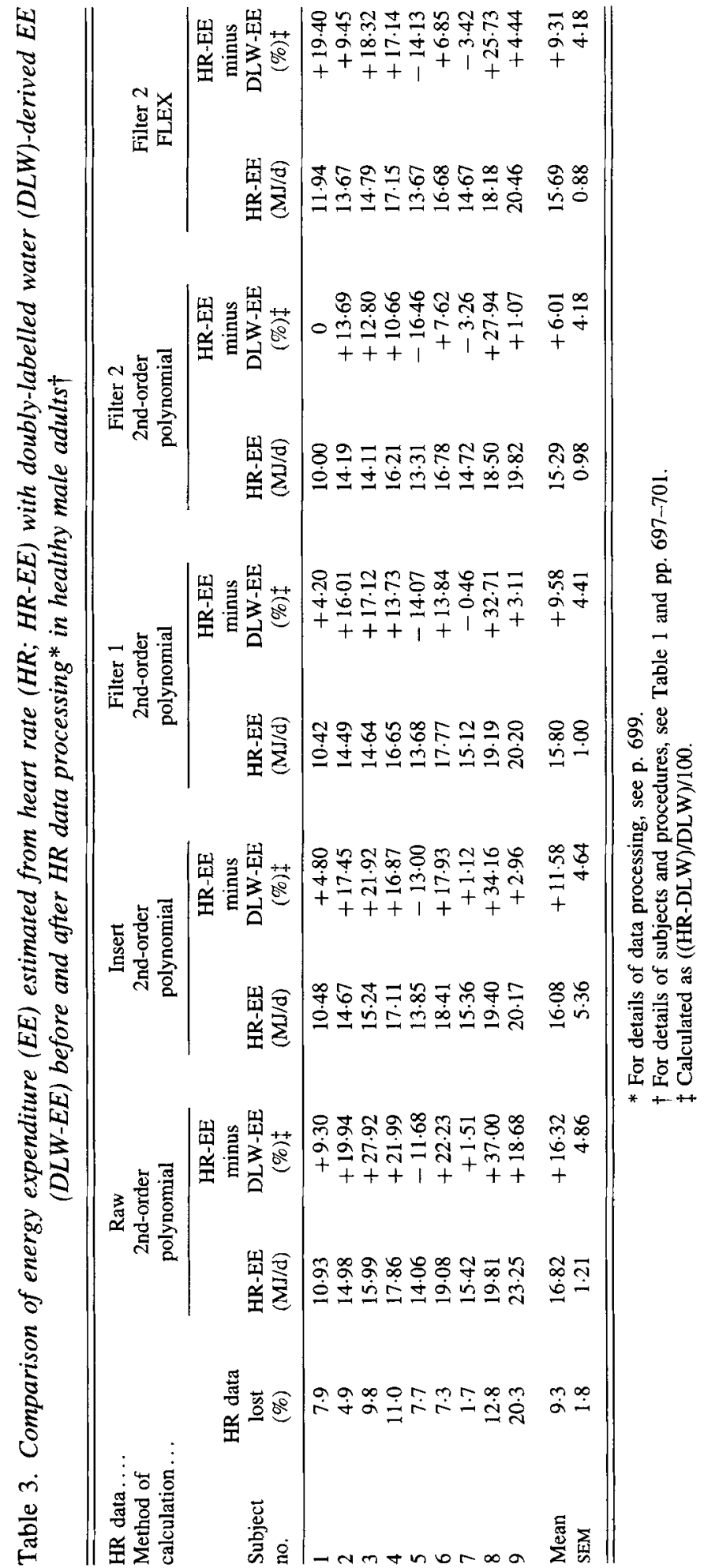


Table 4. Activity diary-derived energy expenditure (EE; $A D-E E)$ and day-to-day variation in heart rate-derived $E E$ (HR-EE) of healthy male adults*

\begin{tabular}{lccccc}
\hline $\begin{array}{l}\text { Subject } \\
\text { no. }\end{array}$ & AD-EE (MJ/d) & $\begin{array}{c}\text { Percentage difference } \\
\text { (AD-EE - DLW-EE) }\end{array}$ & $\begin{array}{c}\text { Day-to-day } \\
\text { HR-EE CV (\%) }\end{array}$ & $\begin{array}{c}\text { Mean weekday } \\
\text { HR-EE (MJ/d) }\end{array}$ & $\begin{array}{c}\text { Mean weekend } \\
\text { HR-EE (MJ/d) }\end{array}$ \\
\hline 1 & 9.29 & -7.10 & 15.11 & 10.21 & 9.34 \\
2 & 10.44 & -16.41 & 6.8 & 14.54 & 12.99 \\
3 & 13.07 & 4.60 & 17.0 & 13.44 & 16.48 \\
4 & 13.51 & -7.72 & 21.3 & 16.00 & 16.93 \\
5 & 11.39 & -28.45 & 15.4 & 13.45 & 12.97 \\
6 & 13.16 & -15.70 & 14.0 & 16.73 & 16.96 \\
7 & 12.44 & -18.10 & 16.8 & 14.50 & 15.50 \\
8 & 15.21 & 5.19 & 21.4 & 17.69 & 21.37 \\
9 & 14.67 & -25.12 & 21.5 & 19.31 & 21.64 \\
Mean & 12.58 & -12.09 & 16.6 & 15.10 & 16.02 \\
SEM & 0.64 & 3.96 & 1.6 & 0.90 & 1.32 \\
\hline \hline
\end{tabular}

DLW-EE, doubly-labelled water method-derived EE.

* For details of subjects and procedures, see Table 1 and pp. 697-701.

$\dagger((\mathrm{AD}-\mathrm{EE}-\mathrm{DLW}-\mathrm{EE}) / \mathrm{DLW}) \times 100$.

the methods $(+6.0($ SEM 4.2$) \%)$ and the difference was again not significant. Expressed in absolute values, as described by Bland \& Altman (1986), the difference between HR-EE following all the previously described improvements (filter 2) and DLW-EE was +1.2 (SEM 0.6) MJ/d. Using the FLEX method for HR-EE calibration, the mean agreement between HR-EE and DLW-EE of +9.3 (SEM 4.2) \% was less good than with the secondorder polynomial equation, although the precision was similar. There was no evidence for a relationship between PAL and the percentage difference between HR-EE and DLW-EE $(r-0.33 ; P>0 \cdot 10)$.

Table 4 shows the individual results for the AD-EE over the same period. Compared with the HR-EE method, the diary-respirometer method showed less good agreement but similar precision. The average difference between AD-EE and DLW-EE was $-12 \cdot 1$ (SEM 4.0) \%, or -1.9 (SEM 0.7) $\mathrm{MJ} / \mathrm{d}$. Table 4 also shows the day-to-day CV in HR-EE which ranged from 6.8 to $21.5 \%$, demonstrating the wide within-subject variation in daily HR-EE in this group. However, this variation does not appear to be explained by differences in EE between weekdays and weekend days, as the mean values were not significantly different $(t-1.54 ; P>0.10)$. There was, however, a tendency for the inactive subjects to have lower values for HR-EE at the weekends than during the week, while the more-active subjects tended to have higher values for HR-EE at the weekends than during the week.

\section{DISCUSSION}

Despite the use of calorimeter-based calibration of HR-EE and continuous HR monitoring, the agreement between HR-EE and DLW-EE in the present study, of +6.0 (SEM 4.3$) \%$, is in broad agreement with other studies comparing HR and DLW in adults (Schulz et al. 1989; Livingstone et al. 1990; Heini et al. 1991; Lovelady et al. 1993). Some difference between the two methods may of course be due to errors in the DLW values. There are many physiological states which may result in errors in the DLW method, although validation studies in this laboratory have. indicated no significant bias in the method at weight stability (Haggarty et al. 1994a). Since the subjects described here were all close to 
energy equilibrium (Haggarty et al. 1994b), we believe that there was no significant bias resulting from physiological processes. The precision of DLW in these subjects was $\pm 3 \%$ (Table 2), whilst the standard deviation of the difference between DLW-EE and HR-EE was $12.6 \%$; therefore, assuming no covariance between HR-EE and DLW-EE methods, the inherent standard deviation in the HR-EE is $12.2 \%$. Comparison of the precision of the HR method with that achievable with the DLW method in the present and other studies is more difficult because the DLW estimates of precision may encompass additional sources of error which are not relevant to the comparison. For example, when using the multi-point method of calculation the final estimate of precision includes a term for the daily variation in $\mathrm{CO}_{2}$ production, but when comparing the two methods it is only the mean $\mathrm{CO}_{2}$ production (or EE) that is of interest. The two-point method employed in the present study does not include a term for daily variation in $\mathrm{CO}_{2}$ production; therefore, comparison of HR-EE with EE estimated using this DLW approach is valid. There are very few other estimates of DLW precision using the two-point method, but the value of $\pm 3 \%$ obtained in these subjects suggests that the DLW method is still a good deal better than HR for estimating the EE of individuals.

In the subjects with very-high-expenditure activities, the difference between the HR during exercise and that during sedentary activities was large. In these subjects the HR-EE calibration curves would have looked more complete with more intermediate points between the very high point and the rest of the data obtained in the respiration chamber, but as these subjects typically performed only one or two high-intensity activities, we felt that it was more important to measure the actual high-intensity activities as they were normally performed, rather than constraining the calibration curve to fit data from activities of intermediate intensity which were not commonly performed by the subjects. Also it was observed that, at the higher levels of EE, the relationship between HR and EE is much less variable for different types of activity than it is at the lower levels of expenditure. It is, however, important when using a second-order polynomial that the highest measured HR and $\mathrm{EE}$ are close to the free-living values, since higher-order polynomials can give rise to large errors when extrapolated outside the range of the data used in their derivation. In the present study, none of the free-living HR values were sufficiently outside the calibration range to introduce a significant error. One way to ensure that the calibration data cover the full range of free-living HR values would be to carry out the HR-EE calibration after inspection of the HR values recorded during the free-living period.

The effect of insertion and filtering of the HR data is evident in the differences between the HR-EE and DLW-EE before and after insertion and filtering of the raw HR data (Table 3; Fig. 3). Most of the data loss occurred because of loss of electrode contact during sleep, when the HR is below the daily average, and this partly explains why the EE derived from the raw HR was significantly greater $(+16 \%)$ than the DLW value. The overestimate was reduced to $+12 \%$ after insertion of $\mathrm{HR}$ values from periods of similar activity, although the overestimate was still statistically significant. The problem of missing HR during sleep could be reduced by extrapolating from the sleeping records which were complete, or by assuming a value for EE during sleep. This requires the subject to make a record of the time spent in bed each night. The proportion of data lost due to artefacts attributable to electrical interference could be overcome by the use of other monitors which do not use a radio transmission link between transmitter and receiver (e.g. Baumann and Haldi monitors; FA, Fleurier, Switzerland).

The subjects in the present study varied from inactive to very active in their leisure time, and it is interesting that the largest error was found in the subject with a PAL of $2 \cdot 36$. This does not support the possibility that the HR-EE method is more accurate in subjects 

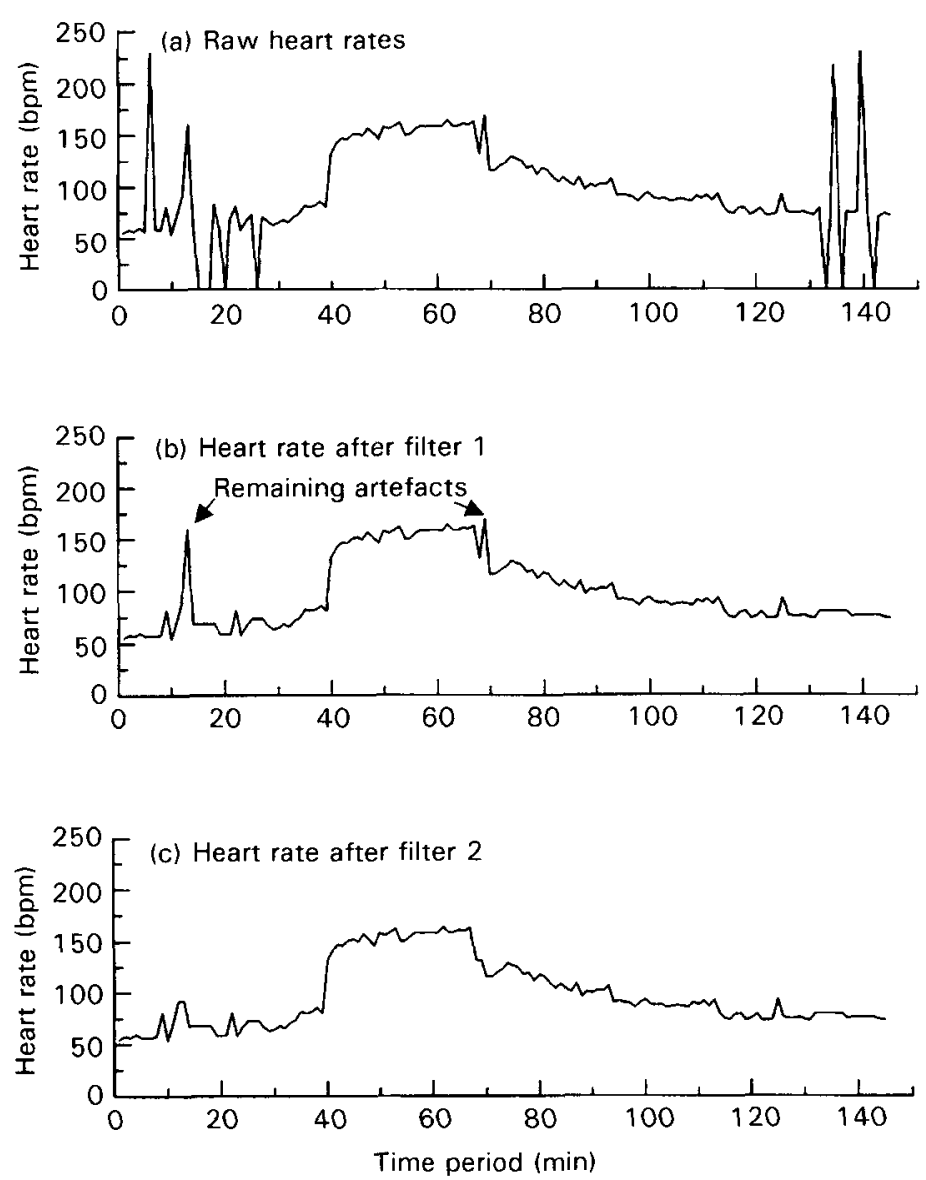

Fig. 3. The effects of filter 1 (b) and filter 2 (c) on artefacts in a section of raw heart-rate data (a). For details of procedures, see p. 699 . bpm, Beats/min.

who spend a larger proportion of their day above resting levels of activity. Of the freeliving studies with DLW shown in Table 1, the best mean agreement between HR and DLW is seen in the study of Maffeis et al. (1995) who measured HR for most of the DLW period in children. Factors which may be more important sources of error in adults than children include the effect of stimulants such as caffeine (Dulloo et al. 1989), consumption of alcohol, and psychological stress (Blaza \& Garrow, 1980). As all the subjects in the present study were non-smokers the effect of nicotine cannot be considered as a source of error, but it could be an important consideration in other groups. The possibility that pharmacological agents and intermittent stress could account for some disturbance of the HR-EE relationship in adults is supported by the fact that the two comparisons of HR-EE with whole-body calorimetry (Spurr et al. 1988; Ceesay et al. 1989) show rather better agreement between methods than do the DLW studies in free-living subjects (Table 1). The effect of postural changes in the HR-EE relationship may also be greater in adults than in children. Development of body position monitors which can record position as sitting, standing, lying or bending forward may help to allow errors introduced by changes in posture, but they will also increase the complexity of the HR method and the calculation of 
the results. However, all these possible refinements to the method cannot remove the variability in both $H R$ and $E E$ at low levels of exercise which has been demonstrated under controlled conditions (Booyens \& Hervey, 1960), which is likely to limit the accuracy with which HR can predict EE over a normal $24 \mathrm{~h}$ period.

Our results confirm the findings of others that the HR-EE method can give reasonable estimates of the $24 \mathrm{~h}$ EE of groups of subjects. However, despite out attempts to improve the calibration of HR-EE and to record HR continuously for the entire DLW measurement period, we still found errors of $20 \%$ or more in individuals. This indicates that the differences between HR-EE and DLW-EE in previous adult studies cannot be explained by the short duration of the HR monitoring, and suggests that the additional effort of the calorimeter and Oxylog calibration may not be justified in most studies. However, the insertion and filtering of the HR data was shown to make a substantial improvement to the HR-EE, so we suggest that they are useful solutions to the problems of loss of electrode contact and electrical interference.

In summary, we suggest that the HR-EE method can be used to estimate the $24 \mathrm{~h}$ EE of groups with reasonable confidence, and that calibration based on $24 \mathrm{~h}$ calorimetry is probably not any major advantage over short-term indirect calorimetry calibration. Insertion and filtering of the data reduced the difference between DLW-EE and HR-EE from 16.3 (SEM 4.9) \% to 6.0 (SEM 4.4) \%, suggesting that these procedures may be useful ways of dealing with interference and loss of contact in the HR records. In this group of subjects the HR-EE values were closer to the DLW-EE values than those obtained from a detailed activity diary and measurements of individual energy costs of selected activities, showing that there is some advantage of the considerable effort involved in the individual calibrations and daily retrieval of HR data. However, the fact that the individual values for $24 \mathrm{~h}$ EE continued to show wide variation around the mean agreement with DLW method suggests that, even if the effect of external stimulants, stress and posture can be adequately accounted for, the HR method is likely to remain less reliable than DLW method for estimating $24 \mathrm{~h}$ EE in individuals. This should not obscure the fact that the HR method provides valuable information on activity patterns and on the intensity of exercise, particularly at levels of exercise above those in sedentary activities. Our view is that, at present, the HR method is best used to provide information on these aspects of physical activity, either as additional information in DLW measurements or in studies which do not require accurate information on $24 \mathrm{~h} \mathrm{EE}$ in individuals.

This research was supported by the Scottish Office Agriculture and Fisheries Department.

\section{REFERENCES}

Bland, J. M. \& Altman, D. G. (1986). Statistical methods for assessing agreement between two methods of clinical measurement. Lancet $\mathbf{i}, 307-310$.

Blaza, S. E. \& Garrow, J. S. (1980). The effect of anxiety on metabolic rate. Proceedings of the Nutrition Society 39, 13A.

Booyens, J. \& Hervey, G. R. (1960). The pulse rate as a means of measuring metabolic rate in man. Canadian Journal of Biochemistry and Physiology 38, 1301-1309.

Bradfield, R. B., Huntzicker, P. B. \& Fruehan, G. J. (1970). Errors of group regressions for prediction in individual energy expenditure. American Journal of Clinical Nutrition 23, 1015-1016

Bukkens, S. G. F. \& McNeill, G. (1990). Comparison of a face-mask and a mouthpiece for measuring resting energy expenditure with the Oxylog. Annals of Nutrition and Metabolism 34, 112-118.

Ceesay, S. M., Prentice, A. M., Day, K. C., Murgatroyd, P. R., Goldberg, G. R. \& Scott, W. (1989). The use of heart rate monitoring in the estimation of energy expenditure: a validation study using indirect whole-body calorimetry. British Journal of Nutrition 61, 175-186. 
Dauncey, M. J. \& James, W. P. T. (1979). Assessment of the heart-rate method for determining energy expenditure in man, using a whole-body calorimeter. British Journal of Nutrition 42, 1-13.

Department of Health (1991). Dietary Reference Values for Food Energy and Nutrients for the United Kingdom. Report on Health and Social Subjects no. 41. London: H.M. Stationery Office.

Dulloo, A. G., Geissler, C. A., Horton, T., Collins, A. \& Miller, D. S. (1989). Normal caffeine consumption: influence on thermogenesis and daily energy expenditure in lean and post-obese human volunteers. American Journal of Clinical Nutrition 49, 44-50.

Emons, J. J., Groenenboom, D. C., Westerterp, K. R. \& Saris, W. H. (1992). Comparison of heart rate monitoring combined with indirect calorimetry and doubly labelled water $\left({ }^{2} \mathrm{H}_{2}{ }^{18} \mathrm{O}\right)$ method for the measurement of energy expenditure in children. European Journal of Applied Physiology 65, 99-103.

Food and Agriculture Organization/World Health Organization/United Nations University (1985). Energy and Protein Requirements. Report of a Joint Consultation. Technical Report Series no. 724 Geneva: WHO.

Haggarty, P., Franklin, M. F., Fuller, M. F., McGaw, B. A., Milne, E., Duncan, G., Christie, S. L. \& Smith, J. S. (1994a). Validation of the doubly labelled water method in growing pigs. American Journal of Physiology 267, R1574-R1588.

Haggarty, P., McNeill, G., Abu Manneh, M. K., Davidson, L., Milne, E., Duncan, G. \& Ashton, J. (1994b). Influence of exercise on the energy requirements of adult males. British Journal of Nutrition 72, 799-813.

Heini, A., Schutz, Y., Diaz, E., Prentice, A. M., Whitehead, R. G. \& Jequier, E. (1991). Free-living energy expenditure measured by two independent techniques in pregnant and non-pregnant Gambian women. American Journal of Physiology 261, E9-E17.

James, W. P. T. \& Schofield, E. C. (1990). Human Energy Requirements. Oxford: Oxford Medical Publications.

Kalkwarf, H. J., Haas, J. D., Belko, A. Z., Roach, R. C. \& Roe, D. A. (1989). Accuracy of heart-rate monitoring and activity diaries for estimating energy expenditure. American Journal of Clinical Nutrition 49, $37-43$.

Leger, L. \& Thivièrge, M. (1988). Heart rate monitors: validity, stability and functionality. The Physician and Sports Medicine 16, 143-151.

Li, R., Deurenberg, P. \& Hautvast, J. G. A. J. (1993). A critical evaluation of heart-rate monitoring to assess energy expenditure in individuals. American Journal of Clinical Nutrition 58, 602-607.

Livingstone, M. B. E., Coward, W. A., Prentice, A. M., Davies, P. S. W., Strain, J. J., McKenna, P. G., Mahoney, C. A., White, J. A., Stewart, C. M. \& Kerr, M.-J. J. (1992). Daily energy expenditure in free-living children: comparison of heart-rate monitoring with the doubly labelled water $\left({ }^{2} \mathrm{H}_{2}{ }^{18} \mathrm{O}\right)$ method. American Journal of Clinical Nutrition 56, 343-352.

Livingstone, M. B. E., Prentice, A. M., Coward, W. A., Ceesay, S. M., Strain, J. J., McKenna, P. G., Nevin, G. B., Barker, M. E. \& Hickey, R. J. (1990). Simultaneous measurement of free-living energy expenditure by the doubly labelled water method and heart rate monitoring. American Journal of Clinical Nutrition 52, 59-65.

Lovelady, C. A., Meredith, C. N., McCrory, M. A., Nommsen, L. A., Joseph, L. J. \& Dewey, K. G. (1993). Energy expenditure in lactating women: a comparison of doubly-labelled water and heart-rate monitoring methods. American Journal of Clinical Nutrition 57, 512-518.

McNeill, G., Bruce, A. C., Ralph, A. \& James, W. P. T. (1988). Inter-individual differences in fasting nutrient oxidation, and the influence of diet composition. International Journal of Obesity 12, 455-463.

McNeill, G., Cox, M. D. \& Rivers, J. P. W. (1987). The Oxylog oxygen consumption meter: a portable device for measurement of energy expenditure. American Journal of Clinical Nutrition 45, 1415-1419.

McNeill, G., McBride, A., Smith, J. S. \& James, W. P. T. (1989). Energy expenditure in large and small eaters. Nutrition Research 9, 363-372.

Maffeis, C., Pinelli, L., Zaffanello, M., Schena, F., Iacumin, P. \& Schutz, Y. (1995). Daily energy expenditure in free-living conditions in obese and non-obese children: comparison with doubly-labelled water $\left({ }^{2} \mathrm{H}_{2}{ }^{18} \mathrm{O}\right)$ method and heart-rate monitoring. International Journal of Obesity 19, 671-677.

Schulz, S., Westerterp, K. R. \& Bruck, K. (1989). Comparison of energy expenditure by the doubly labelled water technique with energy intake, heart rate, and activity recording in man. American Journal of Clinical Nutrition 49, 1146-1154.

Shapiro, S. S. \& Wilk, M. B. (1965). An analysis of variance test for normality (complete samples). Biometrika 52, 591-611.

Spurr, G. B., Prentice, A. M., Murgatroyd, P. R., Goldberg, G. R., Reina, J. C. \& Christman, N. T. (1988). Energy expenditure from minute-by-minute heart-rate recording: comparison with indirect calorimetry. American Journal of Clinical Nutrition 48, 552-559.

Weir, J. B. de V. (1949). New methods for calculating metabolic rate with special reference to protein metabolism. Journal of Physiology 109, 1-9. 